\title{
O Verbo Entoado: Uma breve reflexão sobre a palavra cantada e seus desdobramentos
}

\author{
Jorge Fernando Barbosa do Amaral \\ Universidade Federal do Rio de Janeiro. Centro Universitário Conservatório \\ Brasileiro de Música \\ jfbamaral@gmail.com
}

\begin{abstract}
Resumo: o artigo analisa a palavra cantada como um elemento que comporta, na sua essência, a música e a poesia, mas que, na verdade, é anterior a ambas, pois está na base do processo de manifestação dos sentimentos humanos. Para isso, o trabalho toma como base teórica tanto o pensamento de Jean-Jacques Rousseau (que defende a ideia de que apenas cantando o ser humano consegue, na sua plenitude, se manifestar emocionalmente), quanto o de Luiz Tatit (que encara a canção como uma cristalização dos recursos entoativos da fala). Como o artigo toma como base a palavra cantada no Ocidente, optou-se por um recorte histórico que teve a Idade Média como ponto de partida para as reflexões mais estritamente musicais.
\end{abstract}

Palavras-chave: Música, Poesia, Canção, Idade Média, Palavra.

\section{The Intoned Verb: A brief reflection on the sung word and its consequences}

\begin{abstract}
: the article analyzes the sung word as an element that essentially includes music and poetry, but which actually predates both, as it is the basis of the process of manifestation of human feelings. For this, the work takes as theoretical basis the thought of Jean-Jacques Rousseau, who defends the idea that only by singing the human being can fully manifest emotionally, as the writings of Luiz Tatit, who defines the song as a crystallization of the intonative features of speech. As the article is based on the word sung in the West, it was opted for a historical cut that had the Middle Ages as a starting point for the most strictly musical reflections.
\end{abstract}

Keywords: Music, Poetry, Song, Middle Age, Word.

\section{Prelúdio: breves reflexões históricas}

Grande parte dos autores que se dedicam à história da música ocidental estabelece um corpo canônico que se estrutura a partir do começo na Idade Média. Otto Maria Carpeaux, por exemplo, inicia o seu Livro de ouro da história da música com o coral do Papa Gregório I, do século VI. Curiosamente, segundo Carpeaux, o que se conhece por “coral Gregoriano", no entanto, "não é obra do grande papa. A atribuição a ele só data de 873[...]. Então, o que se cantava na Schola Cantorum de Roma já não era o mesmo como no fim do século VI.” (CARPEAUX, 2001, p. 20). Já Roy Bennnett, por usa vez, ignora esse misterioso hiato de três séculos que separa o Papa Gregório do canto gregoriano e afirma que esse cantochão do século IX é "a música mais antiga que conhecemos, tanto sacra quanto profana" (BENNETT, 2007, p. 13) É obvio, porém, que esses registros 
dizem respeito a certa gênese do cânone musical do ocidente, uma vez que, mesmo sabendo-se das manifestações musicais gregas e judaico-cristãs, é no período medieval que encontramos os mais antigos registros que nos permitiram começar a traçar um perfil técnico e teórico mais preciso da práxis musical do ocidente.

No entanto, é importante dizer que, mesmo na Idade Média, os registros musicais, de uma forma geral ligados à voz humana, estavam confinados ao universo clerical. Fora dela, a música pagã, embora livre dos dogmas religiosos que buscavam evitar os acompanhamentos instrumentais para o canto, estava ainda bastante atrelada à poesia, e os instrumentos serviam basicamente para o acompanhamento dos menestréis e trovadores. Obviamente, há, nessa época, casos de músicas instrumentais, entretanto, é no Renascimento que os instrumentos começam a adquirir autonomia, chegando ao seu primeiro grande momento de independência no período barroco. No período Medieval, pelo menos até o século XII, aproximadamente, a voz ocupava um papel de total supremacia nas manifestações musicais.

Pode-se notar, então, que, independentemente do momento no qual a música ocidental se originou, é certo que suas primeiras manifestações estavam condicionadas à estética vocal. Dentro do universo eclesiástico, a melodia tinha o papel de emprestar ao ser humano uma capacidade de transcender a realidade material, que prendia o homem às limitações terrenas. Era como se, apenas falando, o homem não conseguisse dar conta da grandeza das palavras de Deus. Com o recurso da melodia, porém, a voz humana ultrapassava as amarras da matéria imediata e começava a flertar com o divino. E esse recurso, é importante observar, não era utilizado apenas pelas tradições judaico-cristãs. Várias tradições não ocidentais lançam mão da melodia para ultrapassar a fronteira que separa os universos material e divino, como afirma José Miguel Wisnik:

Pois bem, no mundo modal, isto é, nas sociedades pré-capitalistas, englobando todas as tradições orientais (chinesa, japonesa, indiana, árabe, balinesa e tantas outras), ocidentais (a música grega antiga, o canto gregoriano e as músicas dos povos da Europa), todos os povos selvagens da África, América e Oceania, a música foi vivida como uma experiência do sagrado, justamente porque nela se trava, a cada vez, a luta cósmica e caótica, entre o som e o ruído (WISNIK, 2009, P. 34).

Mesmo assim, até o século VIII, aproximadamente, a música dentro das igrejas era basicamente monofônica, com todos cantando em uníssono uma melodia quase sempre dentro da mesma oitava e sem um ritmo muito definido, pois este era baseado na estrutura 
silábica das palavras. $\mathrm{O}$ resultado era uma melodia muito suave, com caminhos quase sempre traçados por intervalos de um tom, e que procurava deixar a fronteira entre a fala e o canto cada vez mais diluída.

\begin{abstract}
Apesar de o estilo de canto ornado se destinar ao solo, o núcleo do culto cristão é o uníssono de movimento mais lento do cantar de muitas vozes. Essa forma de canto, chamada de cantochão, dominou o culto cristão durante mil anos e ainda hoje é ouvida nas igrejas ortodoxas, católicas e anglicanas. $\mathrm{O}$ cantochão é um cântico melódico simples de textos sagrados, intenso, mas devoto e sereno, extraindo seu ritmo da acentuação natural da linguagem, e seu fraseado da extensão da respiração humana (MENUHIN; DAVIS, 1990, p. 47).
\end{abstract}

A partir do século IX, surgem as primeiras manifestações polifônicas, como o Organum paralelo, que consistia em acrescentar uma segunda melodia com a intenção de duplicar e enriquecer a voz principal. Essa nova linha melódica, chamada de voz organal, era construída com intervalos paralelos, uma quarta ou uma quinta abaixo da voz principal.

Aos poucos, a voz organal foi se tornando mais independente, e nos dois séculos seguintes, se desenvolveu o que se chamou se Organum livre, com vozes contrárias, ou seja, quando a voz principal sobe, a organal desce e vice-versa; vozes oblíquas, isto é, quando uma voz se mantém fixa, a outa se movimenta; e o movimento direto, que ocorre quando as vozes mantêm direções iguais, mas sem a mesma relação intervalar. E no século XII, desenvolve-se o Organum melismático, que se caracteriza pelo prolongamento da voz principal ao mesmo tempo que uma outra se desenvolve suavemente com notas mais curtas.

É importante ressaltar que, à medida que a polifonia fica mais complexa, vão se tornando igualmente complexos os textos entoados a partir dessa melodia. Isso é, se um texto é cantado em uníssono, monofonicamente, ele acaba sendo de mais fácil absorção, ao passo que, ao se acrescentarem as vozes, vão se acrescentando também outros textos, ou até o mesmo texto, mas sempre em contraposição ao texto da voz organal. Essa crescente sofisticação da polifonia começou a se popularizar no ambiente clerical, e, por causa disso, começou a causar certo incômodo nas alas mais conservadoras.

A situação é difícil de esclarecer; enquanto a música harmoniosa, rítmica, compassada, e o acompanhamento instrumental se tornavam cada vez mais comuns, mesmo uma ordem religiosa tão severa como os cistercienses descendente dos beneditinos e criada como protesto contra o que São Bernardo, seu criador, achava ser conforto e luxo da antiga ordem observava em 1217 que em algumas de suas casas os monges estavam 
cantando música a várias vozes, e no século XIV permitia construção de órgãos em suas igrejas. Entretanto, já em 1526, o superior da Ordem na Inglaterra insistia para que a abadia em Thame parasse de cantar música polifônica. Nenhum edito do tipo mais tarde em vigor controlou a música cantada durante a liturgia; não, talvez, que as autoridades estivessem dispostas a tolerar qualquer coisa, mas porque a gama e variedade de práticas em uso nunca foram de todo apreciadas por quem pudesse achar necessário o controle (RAYNOR, 1981. p. 40).

O que se pode observar, então, é que, para os mais conservadores, com a crescente complexificação da polifonia, a música sacra não estava mais restrita apenas à glorificação da mensagem de Deus. Havia, agora, uma perspectiva estética que estava agregada ao caráter divino da música. Esse incômodo das alas conservadoras, é interessante observar, não estava restrito à complexificação da polifonia vocal. A crescente presença dos instrumentos, que aos poucos foram ganhando importância nas missas, também era alvo de protestos, como fez Aeldred, um abade inglês de Rievaulx, no século XII.

Para que tem a igreja tantos órgãos e instrumentos musicais? Para que fim, pergunto, esse terrível soprar de foles, exprimindo mais os estrondos do trovão que a suavidade da voz? Para que servem a contração e infecção da voz (...) enquanto isso, o povo conivente, tremendo e espantado, admira o som do órgão, o ruído dos címbalos e instrumentos musicais, a harmonia da gaita e trombetas (DAVEY Apud RAYNOR, 1981, p. 40).

Nesse contexto, a busca pela transcendência espiritual começava a dialogar intimamente com realidades estéticas cada vez mais ambiciosas. No entanto, ao mesmo tempo em que a relação das vozes ganhava contorno estéticos mais complexos, o texto ia comprometendo seu poder de comunicação. Era como se a estética estivesse tomando a frente das ambições divinas. Assim, se antes a melodia estava a serviço do processo de glorificação da mensagem de Deus, agora, parecia ser um acessório verbal de um projeto musical cada vez mais voltado para sua própria realidade estética, que buscava mais a si mesmo do que ao Criador.

\section{Interlúdio: o monopólio divino}

Até o século XIII, praticamente tudo o que se tinha de registros musicais fora o que a Igreja havia registrado. Durante essa época, o clero mantinha uma espécie de "monopólio oficial" da música. E o resultado disso, claro, foi um sufocamento das manifestações musicais profanas. 
Podemos julgar surpreendentemente que longos séculos de história musical, no decorrer dos quais as melodias litúrgicas adquiriram tal perfeição, não nos tenham transmitido testemunhos de uma música profana (pública ou doméstica). Claro, os tempos não eram propícios, fora dos muros dos mosteiros, ao desenvolvimento de uma arte refinada: invasões, pilhagens, guerras, epidemias construíram por muito tempo o pano de fundo da vida cotidiana. Mas, sobretudo, a função essencial da música era o louvor divino. A supremacia cultural da Igreja, em particular das abadias, era garantida pelo ridículo nível da alfabetização e, sob os carolíngios, pelo apoio do poder político. Preocupada em preservar a pureza de uma arte religiosa, a Igreja não cessava em condenar todas s formas de música profana (CANDÉ, 2001, p. 220).

O curioso é que, apesar disso, uma grande parte do que se tem da música profana também foi recolhida e registrada pela eclesiásticos. Ora, como a Igreja manteve quase que por completo o monopólio sobre as notações musicais, e como havia uma óbvia aversão dessa Igreja pela música profana, os registros desse segmento musical só vieram e ganhar força a partir do século XI. No entanto, "Manuscritos contendo música e poesias seculares em latim aparecem a partir do século IX."1 Mesmo assim, esses registros, geralmente recolhidos por monges, é bastante impreciso. Uma das mais famosas coletâneas de música profana medieval é uma série de poemas e melodias dos séculos XII e XIII, que falavam de vários assuntos, como relacionamentos amorosos, críticas sociais e até mesmo críticas à Igreja. Eles foram descobertos na abadia beneditina de Benedikt-beuren, na Alemanha, em 1803, e que o filólogo germânico Johann Andreas Schmeller intitulou de "Carmina Burana".

Pode-se dizer que, nessa época, praticamente tudo o que se tem de informações de música profana na Europa era resultado da produção, entre outros, de trovadores e nobres, que compunham suas canções, mas que eram levadas para fora dos palácios pelos jograis e menestréis. Curiosamente, eram canções com "melodias que davam clara ideia do tom, mas não dos valores reais das notas, que advinham certamente do ritmo natural das palavras.” (BENNETT, 2007, p.18). Dessa maneira, pode-se imaginar o poder da vertente sonora das palavras no processo de estruturação dessas canções, uma vez que a melodia era, de uma forma geral, o resultado de certa cristalização dos recursos prosódicos da palavra.

\footnotetext{
${ }^{1}$ Extraído do encarte do disco compacto Carmina Burana, do Conjunto de Música Antiga da UFF.
} 


\title{
Poslúdio: palavra cantada, música e poesia
}

De uma forma geral, a civilização ocidental chegou até a Idade Média com a música e a poesia andando juntas. Até esse período, o papel dos instrumentos era pura e simplesmente acompanhar a melodia da voz, que, por sua vez, reinava tão soberana que as primeiras manifestações, digamos, oficiais da música ocidental, manifestada nas igrejas, eram compostas apenas para o canto. Os instrumentos chegaram depois, muito timidamente, como um acompanhamento para as vozes. Obviamente, as exceções sempre existiram, e alguns compositores compunham músicas para apenas para instrumentos. No entanto, esse processo começou a se concretizar de forma mais significativa no Renascimento, até se sacramentar no Barroco. Mas não podemos deixar de pensar que, junto com a soberania musical da voz, veio, claro, a soberania da palavra cantada. Como já foi mencionado, a primeira manifestação musical que conhecemos do ocidente, o Cantochão, era praticamente recitativo, pois dava à palavra o mínimo possível de contornos, praticamente valorizando apenas a música oriunda da própria realidade verbal. No contexto litúrgico, por exemplo, a música adquiriu tal importância na celebração da mensagem divina, que foi necessário a criação de um sistema de escrita musical para fixação do ritual de adoração da palavra de Deus.

\begin{abstract}
A música como elemento de culto, ocupando lugar indispensável no ritual, tem de ser cantada corretamente. Um engano na música do culto, assim como na palavra, gesto ou movimento, podia invalidar a celebração que, portanto, tinha de ser repetida. Por essa razão a música tinha que ser ensinada e ar preciso memorizar as suas formas corretas; métodos de notação tiveram de ser inventados e aperfeiçoados para ajudar a memória dos músicos, de modo que a história da evolução da notação ocidental é a história dos esforços de musicistas eclesiásticos no sentido de assegurar o rigor do ritual (RAYNOR, 1981, p.26).
\end{abstract}

No entanto, ao mesmo tempo em que a música, pagã ou religiosa, estava intimamente ligada à realidade vocal, a poesia, claro, fora das igrejas, estava longe de ser uma manifestação artística autônoma. E o motivo era relativamente simples: o seu desejo de se perpetuar. Até o período medieval, o texto escrito era algo distante da realidade da maioria das pessoas. $\mathrm{O}$ recurso da leitura era um privilégio de alguns poucos nobres e religiosos. Muitos copistas dentro das igrejas, inclusive, se especializavam em reproduzir textos religiosos sendo completamente analfabetos. O trabalho desses monges era simplesmente reproduzir visualmente o que estava escrito, muitas vezes sem saber o conteúdo dos textos. Dessa forma, a poesia, que era natural dos espaços pagãos, estava 
sujeita a morrer com seus autores, já que poucos ouvintes se dedicariam a decorar seus poemas. E a saída para isso era associar esses textos a melodias. Com o auxílio do recurso musical, a poesia se tornaria mais receptiva à memorização, e mais susceptível a se manter na posteridade. Assim, durante certo tempo, música e poesia se mantiveram bastante íntimas. A música, que tinha na voz (e, logo, na palavra) o seu grande objeto de manifestação; e a poesia, que encontrou na música seu grande veículo de perpetuação. Este é um dos fatores, inclusive, que nos ajuda a entender por que praticamente toda a poesia feita na Europa até o fim da Idade Média, segundo Yara Frateschi Vieira, era “composta para ser cantada" (VIEIRA, 1987, p.10).

Obviamente, havia casos de coletâneas escritas dessa produção. A poesia galegoportuguesa, por exemplo, ainda segundo Vieira, "deve ter circulado, na época da sua produção, sob a forma de 'cadernos', ou coletâneas individuais de poesias, normalmente acompanhadas da respectiva pauta musical" (idem, p. 11). De qualquer forma, a poesia falada, ou aquela destinada ao silêncio do papel, só começou a surgir com mais relevância a partir do Renascimento, no século XV. Nesse período, dois fatores foram cruciais para essa separação. O primeiro foi o crescimento da independência dos instrumentos, que passaram a ganhar soberania, não estando mais fadados ao papel de mero acompanhantes do canto. Esse processo, como já dissemos, ganhou força no Renascimento e se sacramentou no período Barroco. O segundo fator foi o surgimento da imprensa, que, aos poucos, popularizou o texto escrito, e acabou funcionando, ainda que timidamente, como mais um veículo de registro do texto poético. Agora o poeta não tinha apenas a melodia como forma de perpetuação de seu texto. Este, agora, podia se fixar no espaço da página.

\footnotetext{
Bemóis e sustenidos têm sido as relações entre a poesia e a música. Ora meio tom abaixo, no tema do sentido. Às vezes, meio tom acima. A lírica do Ocidente (a partir dos trovadores provençais da Idade Média) é um progressivo afastamento do texto e da música que o acompanhava. Com a imprensa, a letra de música emudeceu na página branca. E virou poema (LEMINSKI, 1998, p. 46).
}

É obvio que tudo aconteceu muito lentamente, sobretudo pelo fato de a imprensa ter se estabelecido aos poucos na sociedade, e porque pouquíssimas pessoas sabiam ler. De qualquer maneira, o fato é que, ao se separarem, poesia e música passaram a habitar universos distintos, sobretudo no que diz respeito ao seu caráter representativo. A poesia de livro agora tem apenas a palavra (no caso da poesia contemporânea, é bom que se diga, não apenas ela) como matéria-prima. E, como sabemos, a palavra não é objeto exclusivo 
da prática poética. Assim como outras artes, que têm seus objetos de manifestação tirados da vida cotidiana, a palavra está no mundo para muitas outras coisas. Pode-se escrever histórias, receitas, orações, matérias de jornal, ensaios, enfim, tudo o que se manifesta verbalmente terá a palavra como veículo de manifestação. A poesia, no entanto, levará a palavra a outros níveis de significação. O verbo, no universo poético, será explorado em toda a sua magnitude física, concreta. A sua função primordial de relação conteudística com o objeto terá o mesmo valor que seu aspecto sonoro e (sobretudo na poesia dos séculos XX e XXI) visual. Como pensava Jean-Paul Sartre, a palavra, na prosa, será explorada no seu poder de significar o objeto a que ela se refere. Ao passo que na poesia, ela será tratada mesmo como uma coisa. Algo manipulável sob mais diversos aspectos. O que leva e eleva o verbo a outros níveis de sentido.

No entanto, mesmo se relacionando com a palavra de uma maneira mais ampla que as outras manifestações verbais, a poesia ainda estará, de alguma forma, presa a certa limitação representativa da língua. E isso não acontece com a música. A poesia, neste sentido, está mais próxima de outras formas de arte. A matéria-prima da poesia é a palavra, um elemento que, como já dissemos, está também a serviço de outras manifestações. Assim também é, por exemplo, com a pintura. A tinta e o pincel podem servir para pintar uma casa, por exemplo. O martelo, usado para fazer uma escultura, pode também ser utilizado para produzir uma mesa de escritório... E a música, que matériaprima usaria para se manifestar? A resposta parece simples: ela mesma. E esse talvez seja o grande diferencial da música como manifestação artística. Enquanto as outras artes manipulam objetos que já estão no mundo por outros motivos, a música traz ao mundo a sua própria matéria-prima, o seu próprio objeto. E uma grande prova disso é a existência dos instrumentos musicais. O papel e a caneta, por exemplo, podem ser usados para fazer um poema, mas também podem estar a serviço de um médico na elaboração de seu receituário. O papel e o lápis não estão a serviço exclusivamente da poesia. Mas na música, para que serve um oboé senão para trazer ao mundo um som que nenhum outro objeto seria capaz? Um instrumento musical veio ao mundo apenas para ser instrumento musical. Obviamente, poderíamos usar, por exemplo, um belo violino para decorar nossa sala, mas essa seria uma utilização secundária do instrumento. A priori, um instrumento musical, com exceção, claro, da voz e de alguns objetos utilizados na percussão popular, só existe para se manifestar musicalmente. 
Isso faz com que a música seja soberana como realização artística, estando apenas a serviço de sua própria realidade estética. Por isso, ela não tem a obrigação de significar nada. Ela é o seu próprio significado. É claro que a música pode suscitar emoções, trazer à tona sentimentos, imagens, objetos, situações etc. Mas essa relação quem vai fazer é o ouvinte. Qualquer carga significativa e representativa que possa estar associada à música nunca virá dela (nem mesmo em casos como o do Poema Sinfônico, que são compostos com um propósito significativo explicitado pelo compositor). A música existe apenas para ser ela mesma. Ela reina soberana, e nunca estará a serviço de qualquer processo cristalizado de significação.

É importante salientar, no entanto, que, mesmo quando separadas, música e poesia (e neste caso, pode-se considerar a literatura de uma forma geral) podem manter uma relação da constante proximidade, e até mesmo de cruzamento de caminhos, como afirma Solange Ribeiro de Oliveira, a partir das reflexões de Jean-Louis Cupers.

\begin{abstract}
A música parte de puras abstrações formais, chegando à expressão de estados de espírito e sentimentos e, eventualmente, à tentativa se sugerir objetos e narrativas, como na música pragmática; a literatura, partindo do concreto, do elemento representacional, aventura-se aos poucos a abandoná-lo, buscando atingir a apresentação, a relativa pureza da abstração. Daí resulta a tensão interna das duas artes. O literário, inicialmente representativo, parte para o presentativo; o musical, essencialmente presentativo, caminha em direção ao representativo. A música pragmática se vê narrativa lá onde a literatura descarta o relato, a literatura se quer repetitiva lá onde a música renuncia à repetição (OLIVEIRA, 2002, p. 52-53).
\end{abstract}

Desse modo, a poesia (que, como dissemos, tem, de uma forma geral, a palavra e toda a sua carga conteudística como veículo de manifestação), quando associada ao signo musical, acaba adquirindo também todas as tensões próprias desse universo, pois, segundo o maestro Sérgio Magnani,

[...] O signo musical é portador de tensões: tensões horizontais rítmicomelódicas, tensões verticais contrapontístico-harmônicas, tensões de profundidade dinâmico-timbrísticas. Tais tensões, recebidas e reelaboradas no ato da fruição, transformam-se em outras tantas configurações, adquirindo, em nossa consciência, e aspecto de uma Gestalt ou forma do sentimento. Isto explica por que, para a assimilação da mensagem sonora, não seja indispensável o conhecimento exato da linguagem musical, bastando o exercício de uma sensibilidade apurada, capaz de transformar o jogo das tensões sonoras em uma atividade espiritual subjetiva, quase uma recriação (MAGNANI, 1989, p. 54-55). 
No entanto, se engana quem pensa que essa associação entre palavra e música pode ser algo apenas oriunda de alguma prática conscientemente artística. Essa relação melodia-verbo, segundo o filósofo suíço Jean Jacques Rousseau, se refere a tempos primitivos de aquisição da linguagem. Para ele, a fala, como forma de manifestação das emoções humanas está intrinsecamente atrelada à utilização de recursos melódicos. Segundo o filósofo, o ser humano primitivo, nos primórdios da utilização da linguagem falada, utilizava-se de vários recursos vocais entoativos para se manifestar emocionalmente. Assim, um processo comunicativo pleno em sua expressão era aquele que se aproximava não do seu raciocínio, mas de sua paixão. Para Rousseau "o homem não começou raciocinando, mas sentindo" (ROUSSEAU, 1991, p.163). Ou seja, as diferentes manifestações das emoções humanas estavam ligadas necessariamente ligadas as mais diversas formas de inflexões vocais. Dessa forma, quanto mais retóricas se tornaram as línguas, mais longe elas ficaram da natureza emocional do ser humano. No caso das línguas modernas, a supremacia dos recursos semânticos e gramaticais substituiu a espontaneidade expressiva do ser, distanciando o verbo da voz, e criando aspectos distintos de manifestação.

A escrita, que parece dever fixar a língua, é justamente o que a altera; não lhe muda as palavras, mas o gênio; substitui a expressão pela exatidão. Quando se fala, transmitem-se os sentimentos, e quando se escreve, as ideias. Ao escrever, é-se obrigado a tomar todas as palavras em sua acepção comum, porém, aquele que fala varia suas acepções pelos tons, determinando-as como lhe apraz [...]. Escrevem-se as vozes e não os sons. Ora, numa língua acentuada são os sons, os acentos, as inflexões de toda sorte que constituem a maior energia da linguagem [...] (ROUSSEAU, 1991, p. 170).

O que afirma o filósofo é que a racionalidade da língua acaba sendo inversamente proporcional à manifestação das emoções humanas. Quanto menos sonoridade tiver a língua, mais distante da natureza humana ela vai estar. Isso ratifica a soberania do som na estrutura da linguagem verbal e na plenitude do processo de expressão de sentimentos:

Como as vozes naturais são inarticuladas, as palavras possuiriam poucas articulações, algumas consoantes interpostas, destruindo o hiato das vogais, bastariam para torná-las correntes e fáceis de pronunciar. Em compensação, os sons seriam muito variados, a diversidade dos acentos multiplicaria as vozes; a quantidade, o ritmo, constituiriam novas fontes de combinações, de modo que as vozes, os sons, o acento, o número, que são da natureza, deixando as articulações, que são convenções, bem pouco a fazer, cantar-se-ia em lugar de falar (ROUSSEAU, 1991, p. 166). 
Dessa forma, então, devido ao alto grau de importância das inflexões vocais para a plena expressão das emoções, o ser humano primitivo, para Rousseau, em vez de falar, cantava. E isso nos faz chegar à conclusão de que a origem da linguagem verbal está necessariamente atrelada à origem da música, sobretudo no seu aspecto melódico:

\begin{abstract}
A princípio não houve outra música além da melodia, nem outra melodia que não o som variado da palavra; os acentos formavam o canto, e as quantidades, a medida; falava-se tanto pelos sons e pelo ritmo, quanto pelas articulações e pelas vozes (ROUSSEAU, 1991, p. 187).
\end{abstract}

Apesar de tudo, embora a importância do som no processo de estabelecimento da comunicação verbal tenha decrescido, o elemento melódico continua intrínseco ao ato de falar. Pode-se dizer que, ainda nos dias de hoje, os recursos sonoros são de extrema importância em muitos momentos da linguagem falada. Se na escrita podemos lançar mão de diversos sinais gráficos para determinar a intenção de um enunciado, será a entonação (e, nesse contexto, por que não, o canto) que, na fala, determinará, por exemplo, se perguntamos: "Chegou alguém?" ou se afirmamos: "Chegou alguém!". Por isso, Rousseau atribui uma importância bastante singular às canções. Uma vez que, no canto, o verbo se reúne à melodia, e restabelece a capacidade da língua de se comunicar em toda sua plenitude.

Nesse contexto de intimidade entre a fala e o canto, o professor, linguista e compositor Luiz Tatit defende que, ao mesmo em que a fala é uma forma cotidiana e instável de manifestação musical, o canto é uma manifestação cristalizada dos recursos entoativos da fala. Assim, pode-se dizer que Rousseau e Tatit, apesar de estarem diacronicamente distantes, seguiram caminhos analíticos similares, pois, se para o primeiro, a canção é o restabelecimento dos laços essenciais do processo de comunicação, para o segundo, a fala, se cristalizada melodicamente, adquire o poder de se perpetuar da consciência ouvinte. 
Todos nós, falantes da língua, produzimos "canções" (entoações + frases verbais) que em geral não merecem ser fixadas. Ao contrário, tendem a ser esquecidas logo após a comunicação. No entanto, alguns de nós provavelmente levados por ímpetos artísticos, consideramos que vale a pena perenizar trechos dessas falas de modo que possam ser repetidos e até cantarolados em coro pelas pessoas. É quando nos pomos a compor. Claro que essa atividade envolve também uma certa habilidade musical, não no sentido instrumental do termo (ninguém precisa tocar bem para compor), mas no sentido de capacidade de fixação dos contornos entoativos para que esses não desapareçam juntamente com nossas falas cotidianas. Envolve, simultaneamente, uma capacidade de fixação das frases linguísticas que, na maior parte das canções, também são criadas na tangente da linguagem oral. Por isso, "como é bom poder tocar um instrumento!" ele ajuda a estabilizar o que é naturalmente instável (TATIT, 2007, p. 414).

Segundo Tatit, tanto fala quanto canto são formados por certas propriedades da língua que são estruturadas por cadeias fônicas específicas. No que diz respeito à fala, essa cadeia (composta de sons desorganizados) é imediatamente descartada assim que cumpre seu papel de apenas concretizar determinado ato comunicativo. Já na canção, existe uma organização mais rígida, pois, agora, há o objetivo de instalar certa estabilidade sonora no ato da comunicação. Na canção, mais do que um ato de se comunicar, há a intenção de se perpetuar a mensagem. Assim, como afirma Tatit, "fazer uma canção é também criar uma responsabilidade sonora” (TATIT, 1996, p. 12), por isso "alguma ordem deve ser estabelecida para assegurar a perpetuação sonora da obra, pois seu valor, ao contrário do colóquio, depende disso" (TATIT, 1996, p. 12). Foi esse poder de se perpetuar na consciência do indivíduo (a partir de uma mensagem verbal carregada de tensões musicais) que fez com que a canção suportasse a separação entre a poesia e a música, e continuasse firme e se renovando até os dias atuais. E tal fato ocorre porque ela é orgânica, natural do ser humano e anterior a qualquer reflexão sobre a gênese da música ou da poesia. Por isso a palavra cantada pode fazer com que o ser humano eleve sua voz aos céus, perpetue sua mensagem na consciência do outro, e, no sentido mais essencial, se expresse emocionalmente em toda a sua plenitude. 


\section{Referências}

BENNETT, Roy. Uma breve história da música. Tradução: Maria Teresa Resende Costa. Rio de Janeiro: Jorge Zahar Editor, 2007.

CANDÉ. Roland de. História Universal da Música. Vol. 1. São Paulo: Martins Fontes, 2001.

CARPEAUX, Otto Maria. O livro de Ouro da história da música: da Idade Média ao século XX. $2^{\mathrm{a}}$ ed. Rio de Janeiro: Ediouro, 2001.

LEMINSKI, Paulo. Vida. Porto Alegre: Sulina, 1998.

MAGNANI, Sergio. Expressão e comunicação na linguagem da música. Belo Horizonte: Editora UFMG, 1989.

MENUHIN, Yehudi; DAVIS, Curtis W. A música do homem. $2^{\mathrm{a}}$ ed. São Paulo: Martins Fontes, 1990.

OLIVEIRA, Solange Ribeiro de. Literatura e música: Modulações pós-coloniais. São Paulo: Editora Perspectiva, 2002.

RAYNOR, Henry. História social da música. Rio de Janeiro: Zahar Editores. 1981.

ROUSSEAU, Jean-Jacques. Ensaio sobre a origem das línguas. In: Os pensadores. Tradução por Lourdes Santos Machado; introdução e notas de Paul Arbousse-Bastide e Lourival Gomes Machado. 5 ed. São Paulo: Nova Cultural, 1991.

TATIT, Luiz. O Cancionista: Composições de Canções no Brasil. São Paulo: Edusp, 1996.

TATIT, Luiz. Todos entoam: Ensaios, conversas e canções. São Paulo: Publifolha, 2007.

VIEIRA, Yara Frateschi. Poesia Medieval: Literatura portuguesa. São Paulo: Global Editora, 1987.

WISNIK, José Miguel. O som e o sentido. $2^{\text {a }}$ ed. $7^{\text {a }}$ reimp. São Paulo: Companhia das Letras, 2009. 
RevistaMúsica, v. 20 n. 2 - Dossiê Música em Quarentena Universidade de São Paulo, dezembro de 2020 ISSN 2238-7625 